\title{
Meralarda Farklı Otlatma Yoğunluklarının Bastırılmış Ot Katı Yüksekliği ve Ak Üçgülün (Trifolium repens L.) Görülme Sıklığına Etkisi
}

\author{
Nurdan ŞAHIN DEMIRBAĞ ${ }^{1}$
}

Geliş Tarihi: 13.06.2007

\begin{abstract}
Öz: Amaç, devamlı otlatılan meralarda, orta-yoğun ve hafif otlatmada bastırımış ot katı yükseklik gruplarının dağı̆ımı ve bu yükseklik grupları içerisinde ak üçgülün (T.repens) görülme sıklığını 4 farklı gözlem döneminde karşılaştırmaktır. Çalışma, bir Avrupa Birliği Projesi olarak, Almanya Göttingen Üniversitesi uygulama çiftliğinin "dışarıdan girdi kullanmadan işletilen, devamlı otlatılan merasında 2002-2003 yılları arasında kısırlaştııımış erkek Simmental sığır ırkıyla yürütülmüştür. Mera orta-yoğun otlatma $(\mathrm{OO})$ ve hafif otlatma $(\mathrm{HO})$ şeklinde ikiye bölünmüş, ilk yıl otlatılan merada, denemenin 2. otlatma yılında elde edilen veriler değerlendirilmiştir. Deneme üç tekrarlı olarak kurulmuştur ve her bir parsel büyüklüğü 1 hektardır. OO'da hedeflenen bastırımış ot katı yüksekliği (BY) $6 \mathrm{~cm}$, HO'da $12 \mathrm{~cm}$ 'dir. Her parselde 100 metre uzunluğundaki ölçüm hattında, bir metre aralıklarla sabitlenen ölçüm noktalarında, otlatma periyodunun başlangıcından itibaren 4-5 haftada bir tekrarlanan 4 farklı gözlem döneminde, diskmetre ile her gözlem noktasındaki bastırımış ot katı yüksekliği ölçülmüş ve o ölçüm noktasında ak üçgülle karşılaşılıp karşılaşılmadığı kaydedilmiştir. Bastırılmış ot katı yükseklikleri (BY1: $\leq 4.5 \mathrm{~cm}$, BY2: $5.0-9.5 \mathrm{~cm}$, BY3: $10.0-14.5 \mathrm{~cm}$ ve BY4: $\geq 15.0 \mathrm{~cm}$ şeklinde 4 farklı yükseklik grubuna ayrılmış ve bu grupların farklı otlatma yoğunlukları altındaki dağılımı ve ak üçgülün görülme sıklığı hesaplanmıştır. En yüksek rastlanma sıklığı BY2 grubunda (\% 40.9), en düşük rastlanma sıklığı BY4 grubundadır (\%10.7). Otlatma sistemi x BY grup interaksiyonunda OO sisteminde en yüksek rastlanma sıklığı BY2 grubunda(\% 41.1), en düşük BY4 grubunda (\% 5.7), HO sisteminde BY2 (\% 40.8) en yüksek, en düşük BY1 grubundadır (\% 9.7). BY grubu $x$ dönem intereksiyonunda ise en yüksek rastlanma sıklığı BY2 grubunda 1. dönemde (\% 53.8), en düşük rastlanma sıklığı 1.dönemde BY4 grubunda (\% 2.7) elde edilmiştir. Ak üçgülün rastlanma sıklığı BY1'de en yüksek (\% 79.3), BY4'te en düşüktür (\% 36.7). Otlatma yoğunluğu x Dönem interaksiyonu açısından, ak üçgülün rastlanma sıklığı sadece $O O$ sisteminin 1. döneminde anlamlı farklılık göstermiştir. Ak üçgülün görülme sıklı̆ı, kısa BY gruplarında ve orta yoğun otlatma sisteminde, uzun boylu gruplara ve hafif otlatmaya göre, daha fazla olma eğilimindedir. Sonuçlar, ak üçgülün kısa boylu bitkilerden oluşan bastırılmış ot katı yükseklik gruplarında ve vejetasyonda oluşabilecek bitkisiz bölgelerde daha iyi gelişebileceğini göstermektedir. Oluşabilecek parçalı (mozaik) yapıdaki heterojen mera örtüsü ak üçgülün gelişimini olumlu şekilde etkileyebilir.
\end{abstract}

Anahtar Kelimeler: T.repens, ak üçgül, orta-yoğun otlatma, hafif otlatma, bastırımış bitki boyu

\section{The Effect of Different Grazing Systems on Compressed Sward Height and White Clover (Trifolium repens L.) Frequency in Grasslands}

Abstract: The aim of this study is to determine and compare of the frequency of sward structure and the frequency of white clover (Trifolium repens L.) between intensively-grazed (MC,Moderate Commertial Stocking) and extensively-grazed (LC,Lenient Commertial Stocking) grasslands. Study was carried out as an EU project at Göttingen University in extensively and continuously grazed Relliehausen Experimental Grassland in Germany in 2002-2003 with three repetitions and commercial castrated simmental breed. Grassland was randomized into two continuous stocking groups as MC (intensive grazing with moderate stocking) and LC (extensive grazing with lenient stocking), and after 1st year grazing, data was collected from second year's records. Study was planned as 3 repetitions and each plot was composed of 1 ha. Targetted compressed sward heights $(\mathrm{CSH})$ were $6 \mathrm{~cm}$ in MC and $12 \mathrm{~cm}$ in LC. CSH measurements were collected from previously fixed 100 points by transect method, spaced $1 \mathrm{~m}$ in transect line composed of $100 \mathrm{~m}$ in each plot with 4 repetitions in 4 period in every 4-5 weeks by using discmeter and identified white clover was also recorded. Measured CSH levels was recoded as CSH1: $4.5 \mathrm{~cm}, \mathrm{CSH} 2: 5.0-9.5 \mathrm{~cm}, \mathrm{CSH} 3: 10.0-14.5 \mathrm{~cm}$ and $\mathrm{CSH} 4: \geq 15.0 \mathrm{~cm}$. The highest incidence was seen in $\mathrm{CSH} 2$ group (40.9\%) and the lowest one was in $\mathrm{CSH} 4$ group $(10.7 \%)$. In MC system, the highest incidence was seen in $\mathrm{CSH} 2(41.1 \%)$ the lowest in CSH4 (5.7\%); in LC system the highest in $\mathrm{CSH} 2(40.8 \%)$, the lowest in $\mathrm{CSH} 1(9.7 \%)$ in respect to grazing system and $\mathrm{CSH}$ group interaction. Also the highest incidence was seen in $\mathrm{CSH} 2$ and in the $1^{\text {st }}$ period $(53.8 \%)$, the lowest in $\mathrm{CSH} 4$ and in the $1^{\text {st }}$ period

Ankara Üniv. Ziraat Fak. Tarla Bitkileri Bölümü-Ankara 
(2.7\%) according to CSH group and period interaction. Frequency of white clover was the highest in CSH1 $(79.3 \%)$, and the lowest in CSH4 (36.7\%) and, also showed statistically significant difference in only MC system and $1^{\text {st }}$ period according to $\mathrm{CSH}$ group and period interaction. Frequency of white clover showed a tendency to increase in short CSH groups and in MC than those tall CSH groups and LC. In conclusion, white clover can survive in grasslands in short $\mathrm{CSH}$ groups or bare soil sites of grasslands and heterogenious-mosaic sward structure of grassland may effect the growth of white clover positively.

Key Words: Trifolium repens, white clover, sward structure, moderate stocking, lenient stocking, compressed sward height

\section{Giriş}

Günümüzde yoğun işgücüne intiyaç duyan ekim nöbeti meraları yerine, daha az masraflı olan devamlı meralarda hayvan otlatmak alternatif olarak görülmektedir. Çitlerle çevrilmiş meralarda hayvanlar tüm otlatma mevsimi süresince ya da en azından uzun otlatma dönemlerinde merada kalabilmektedirler (Geisler 1980). Devamlı meraların özelliği, bitk gelişiminin sezon boyunca farklılık göstermesidir. Sonuçta, sezon içinde yem fazlalığından bile söz edilebilir (Yem üretimi > Yem intiyacı). En fazla bitki büyüme oranı ilkbaharda olmaktadır (Opitz von Boberfeld 1994).

Başarılı bir otlatma için meradaki hayvan yoğunluğu ile değişen bitki büyüme oranı arasındaki uyuma dikkat edilmelidir (Nösberger ve Opitz von Boberfeld 1986). Eğer meradaki hayvan baskıs nispeten düşük tutulursa elbette mera bitki örtüsü de otlatmadan 0 derecede az zarar görecektir. Diğer taraftan mera üzerinde artan hayvan yoğunluğu, mera otunun kalitesini iyileştirir (Geisler 1980). Meradak hayvanlara heterojen bir bitki örtüsü sunuluyorsa, "otlatmanın hayvanlarca tercihli yapılması işlemi" başarılmış olur. Hayvanlar lezzetli buldukları bitkileri daha sık otlarken, diğer bitkileri otlamaktan kaçınırlar ve böylece belirli bitkileri seçerek otlamış olurlar. Hafif otlatma baskısı altında tercih edilmeyen bitkiler gelişip büyüyebilirler (Bakker 1998). Bu şekildeki (seçici) otlama, mera bitki örtüsünün bazı kısımlarında istenmeyen bitkilerin aşırı gelişimine neden olur. Bazı kısımlarda ise, tercih edilen bitkiler aşırı dipten otlanmış olarak kalır.

Uzun boylu bitkilerin bulunduğu bitki topluluklarındaki yüksek rekabet bazı bitki türlerinin gelişimini olumsuz etkiler. Bu noktada karar verici olan, istenen ve istenmeyen bitkinin mera için taşıdığı anlamdır. Örneğin ak üçgül (Trifolium repens L.) bitkisinde olduğu gibi.

Ilıman iklim bölgelerindeki daimi meralarda, ak üçgül en önemli baklagil yem bitkisidir. Ak üçgülün gen merkezi Akdeniz bölgesidir. Ancak dağlık bölgelere kadar dağılım göstermektedir. Dünyada Akdeniz iklimi bölgelerinde yem bitkisi olarak yetiştirilmektedir (Keller ve ark. 1999).

Ak üçgül en iyi otlatılabilen üçgül türüdür (Nösberger ve Opitz von Boberfeld 1986). Uzun ömürlü, kışa yeterince dayanıklı, iyi bir uyum yeteneğine sahip olması, toprağa azot bağlaması, otlatma baskısına ve çok biçmeye dayanıklı olması ve oldukça hızlı çoğalma yeteneği nedeniyle ak üçgül özellikle devamlı meralarda ve buğdaygillerle karışım yapılabilen üçgüller arasında en önemli üçgül türüdür. Çayırlarda uzun boylu buğdaygillerin ışık eksikliğine neden olması yüzünden, ak üçgül bitkisinin gelişimi engellenir. Ancak bu durumu dikkate alınarak çayırlarda kullanımı uygun olabilir (Opitz von Boberfeld 1994). Ak üçgül toprakta sıkı sürünücü gövde meydana getirerek büyür. Sülüklerdeki dallanma ve enine büyüme sayesinde yaprak ve yan kökler geliştirerek yayılabilir (Keller ve ark. 1999).

Yüksek sıcaklık, az ışık yoğunluğu veya gölgelenmeyle ak üçgül büyük yapraklar üretir (Parsons ve ark. 2000). Nemli toprakları ağır topraklardan daha çok tercih eder, kuru topraklar gelişimi için uygun değildir (Nösberger ve Opitz von Boberfeld 1986). Ak üçgül gibi sülüklü bitkilerde besin maddesi alımı ve besin maddesi elverişliliği için toprağın yapısı önemlidir. Çünkü ak üçgül adventif kökleri ile toprağın üst kısmından daha çok yararlanabilmektedir. Ak üçgülün gelişiminde komşu bitkilerin ya da kendi yapraklarının gölgelemesi, yani ışığın nitelik ve niceliği önemlidir. Dik gelişen bitkiler uzun gövdeleri ile gölgelenmeye karşı koyabilirler. Gölgelenmeye karşı koyma, temelde yatay büyüme tiplerinde mümkün değildir. Yapraklar sadece mevcut olan bitki yüksekliğine kadar belli bir açı ile uyum sağlamışlardır (Stoffel 1997). Burdan yola çıkarak, ak üçgülün öncelikle kısa boylu ve aşırı sık olmayan bitki örtüsü içinde ortaya çıkabileceği tahmin edilebilir.

Çalışmanın amacı, orta ve hafif otlatma yoğunlukları altında devamlı otlatılan bir merada, otlatma mevsimi boyunca bastırılmış ot katı yükseklik gruplarının ve bu yükseklik grupları içerisinde ak üçüüün görülme sıklığını karşılaştırmaktır. 


\section{Materyal ve Yöntem}

Araştırma Göttingen Üniversitesi Rellihausen sun merasında, 2002-2003 yılları arasında 2 yıl süreyle yürütülmüştür. Mera bitki örtüsü tipi LolioCynosuretum'dur. Mera son 10 yılda hiç gübrelenmemiş, böcek ve bitki öldürücü kullanılmamıştır. Mera orta $(\mathrm{OO})$ ve hafif $(\mathrm{HO})$ olmak üzere iki farklı yoğunlukta otlatımıştır. Orta otlatmada hedef bitki örtüsünün yüksekliğinin $6 \mathrm{~cm}$, hafif otlatmada ise $12 \mathrm{~cm}$ olması amaçlanmıştır. Ot katı yüksekliği haftalık olarak diskmetre ile tespit edilmiştir (Castle 1976). Hedef yükseklik hayvan baskısı ile uyumlu hale getirilmiştir. Araştırmada ortalama 8-10 aylık kısırlaştırımış erkek Simmental ırkı sığırlar kullanılmıştır.

Otlatma kapasitesi açısından birim alana düşen hayvan yoğunluğu orta $(O O)$ otlatmada 3,6 hayvan/ha ve hafif $(\mathrm{HO})$ otlatmada 1,5 hayvan/ha olarak planlanmıştır.

Her iki otlatma yılında da (2002-2003) otlatma nisan-ekim ayları arasında yapılmış ve sonuçlar Nisan 2003-Temmuz 2003 arasındaki 4 farklı gözlem aralığına ait veriler üzerinden değerlendirilmiştir.

1- Gözlem aralığı: 28.04.2003 - 09.05.2003

2- Gözlem aralığı: 02.06.2003 - 10.06.2003

3- Gözlem aralığı: 30.06.2003-03.07.2003

4- Gözlem aralığı: 28.07.2003 - 31.07.2003

Bu otlatma mevsimine ait aylık sıcaklık ve yağış miktarları Şekil 1'de görülmektedir.

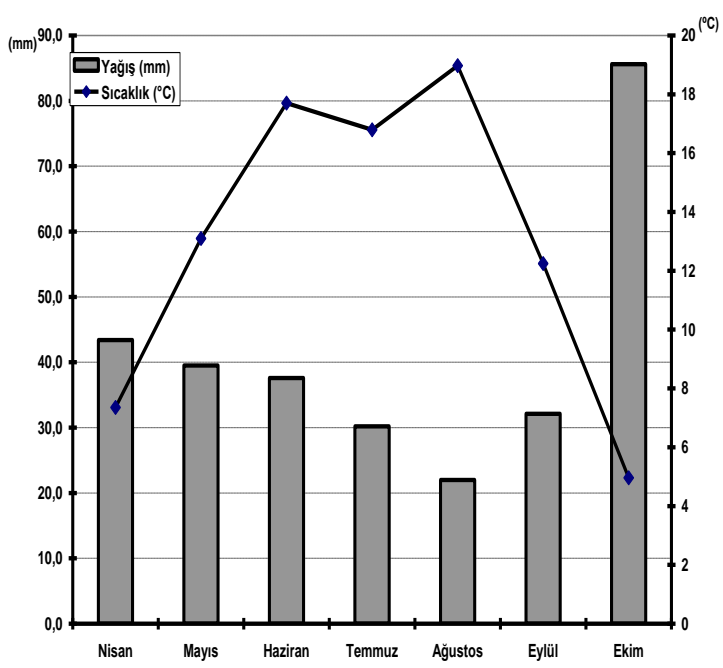

Şekil 1. Otlatma mevsimi boyunca 2003 yılına ait aylık sıcaklık $\left({ }^{\circ} \mathrm{C}\right)$ ve yağış miktarları $(\mathrm{mm})$
Otlatma mevsimi (2003) yağışlı bir sezon olan 2002 yılına göre daha kurak olarak geçmiştir.

Deneme üç tekrarlıdır. Her bir parsel 1 hektar büyüklüğündedir. Her parselde $100 \mathrm{~m}$ uzunluğundaki ölçüm hatları üzerinde, $1 \mathrm{~m}$ aralıklarla, herbir gözlem karakteri için toplam 100 ölçüm değeri elde edilmiş ve bu ölçüm noktaları tüm otlatma mevsimi boyunca sabitlenmiştir. Otlatma mevsiminin başlangıcından itibaren 4-5 haftalık dönemler halinde sabitlenen ölçüm hatlarında gözlemler yapılmıştır. Her bir gözlem noktasında bastırımış ot katı yüksekliği (boyu) (Compressed sward height $=\mathrm{CSH}$ ) Rising plate meterDiskmetre ile Castle (1976)'a göre ölçülmüştür. Bu ölçüm aleti ile bitki kompozisyonunun karşı koyma gücüne, yoğunluğuna ve yüksekliğine göre, hareketli, $200 \mathrm{~g}$ ağırlığında, $30 \mathrm{~cm}$ çaplı metal kısmı ile dik bir şekilde bitki kümesi üzerinde bastırılarak, birimlendirilmiş sopası üzerinden bastırılmış ot katı yüksekliği ölçülmüştür. Ölçülen bu mera bitki örtüsü yüksekliği, 4 farklı bastırılmış ot katı yükseklik grubuna ayrılmış ve 'bastırılmış yükseklik= BY' olarak kısaltılmış (BY1: $\leq 4.5 \mathrm{~cm}$, BY2:5.0-9.5 cm, BY3:10.0$14.5 \mathrm{~cm}$ ve $B Y 4: \geq 15.0 \mathrm{~cm}$ ) ve bu 4 farklı grubun meradaki iki farklı otlama yoğunluğu altındaki sezon boyunca göstermiş olduğu dağılım ve değişim kaydedilmiştir.

Bastırılmış ot katı yüksekliği yanında, hat üzerinde ölçüm yapılan her noktada, ölçü aletinin metal kısmının altında ak üçgülle karşılaşılıp karşılaşılmadığı belirlenmiştir ve tüm bitki örtüsü yükseklik gruplarına oranlanarak merada ak üçgülün görülme sıklığı hesaplanmıştır.

Sonuçar kodlanarak SPSS for Windows 13.0 ortamında bilgisayara kaydedilmiştir. Denemede farklı otlatma yoğunlukları (OO ve $\mathrm{HO}), 4$ farklı bastırılmış ot katı yükseklik grubu ve 4 farklı gözlem dönemi olmak üzere 3 farklı faktör ele alınmıştır. Bu faktörlerden dönem, tekrarlanan ölçüm içeren faktördür. Bastırılmış ot katı yükseklik grupları ve ak üçgülün görülme sıklığı üzerine farklı otlatma yoğunluklarının etkisi tekrarlanan ölçümlü varyans analizi modeli (repeated measurement design) kullanılarak karşılaştırma yapılmıştır. Ancak veriler normal dağılım göstermediği için, yüzde değerlere "sinus açı transformasyonu" uygulanıp daha sonra tekrarlanan ölçümlü varyans analize tabi tutulmuştur. Tekrarlanan ölçümlü varyans analizi sonrası istatistiksel farkın anlamlı bulunduğu durumlarda, farkın hangi ikiliden kaynaklandığı Duncan post hoc çoklu karşılaştırma testi ile belirlenmiştir. Bütün testlerde $\mathrm{P}<0.05$ istatistiksel olarak anlamlı kabul edilmiştir. Çoklu karşılaştırma testinde sinüs açı değerine çevrilmiş veriler üzerinde farklı grupların harflendirilmesi yapılmıştır ancak tablolar gerçek ortalamaları göstermektedir. 


\section{Bulgular}

Şekil 2 ve Şekil 3' te dört farklı mera bastırılmış ot katı yükseklik grubunun orta yoğun ve hafif otlatma sistemlerinde dört farklı gözlem tarihinde ortaya çıkma sıklığı verilmiştir. Bu şekillere göre, hafif otlatmada yüksek boylu bitki bastırılmış ot katı grupları (BY2 ve BY3), orta otlatmada kısa boylu bitki bastırılmış ot kat yükseklik gruplarının (BY1 ve BY2) daha fazla ortaya çıktığı görülmektedir.

Her iki otlatma sisteminde de BY4 grubu, BY3 grubuna göre, daha az oranda temsil edilmektedir.

OO sisteminde ilk iki dönemde BY1 ve BY2 grupları toplam \%70 civarında iken, 3. ve 4. dönemlerde \%80'in üzerine çıktığı görülmektedir. HO otlatma sisteminde ise BY2 ve BY3 gruplarının mera yüksekliğine hakim oldukları görülmektedir. Hem $\mathrm{OO}$ hem de $\mathrm{HO}$ otlatma sisteminde, 1. dönemde BY2 grubu en sık rastlanılan grup (OO için; \%58,3, HO için $\% 49,3$ ) olarak tespit edilmiştir.

İki farklı otlatma yoğunluğu altında ve farklı dönemlerdeki bastırılmış ot katı yükseklik gruplarının dağılımlarına ait çoklu karşılaştırma testi sonucundaki grup ortalamaları ve harflendirmeleri Çizelge 1'de verilmiştir. Buna göre, merada bastırılmış ot katı yükseklik grubu (BY) dağılımında, "BY grubu", "otlatma yoğunluğu x BY grubu" ve "BY grubu x Dönem" interaksiyonu \% 1 seviyesinde önemli, diğer faktörler ve muhtemel ikili ve üçlü interaksiyonların ortalamaları arasında istatistiksel olarak anlamlı fark tespit edilmemiştir.

BY grupları bakımından \% 40.9 ile BY2 grubu en yüksek rastlanma sıklığını alırken, BY3 ve BY1 grupları bunları takip etmiş ve \%10.7 değeri ile BY4 grubu en az rastlanma sıklığı değerini vermiştir. "Otlatma yoğunluğu x BY grup" interaksiyonunda en sık rastlanma sıklığı \% 41.1 ile orta otlatma yoğunluğunda BY2 grubunda olurken, bunu \% 40.8 ile aynı BY grubunda hafif otlatma sistemi vermiştir. OO sistemindeki BY1 \% 36.1 rastlanma sıklığı ile en yüksek değeri alırken, aynı BY grubunun (BY1) HO sisteminde kendi otlatma sistemi içinde \% 9.7 ile en düşük rastlanma sıklığı gösterdiği görülmektedir. "Otlatma sistemi x BY grubu" interaksiyonunda en düşük rastlanma sıklığı $\% \quad 5.7$ ile $\mathrm{OO}$ otlatma sisteminde BY4 grubunda belirlenmiştir.

"BY grubu x dönem" intereksiyonunda ise en yüksek rastlanma sıklığına \% 53.8 ile BY2 grubunda 1 . dönemde ulaşıldığı, diğer grupların bunların arasında yer aldığı ve \% 2.7 ile 1. dönemde BY4 grubunda en düşük rastlanma sıklığı elde edildiği görülmektedir.

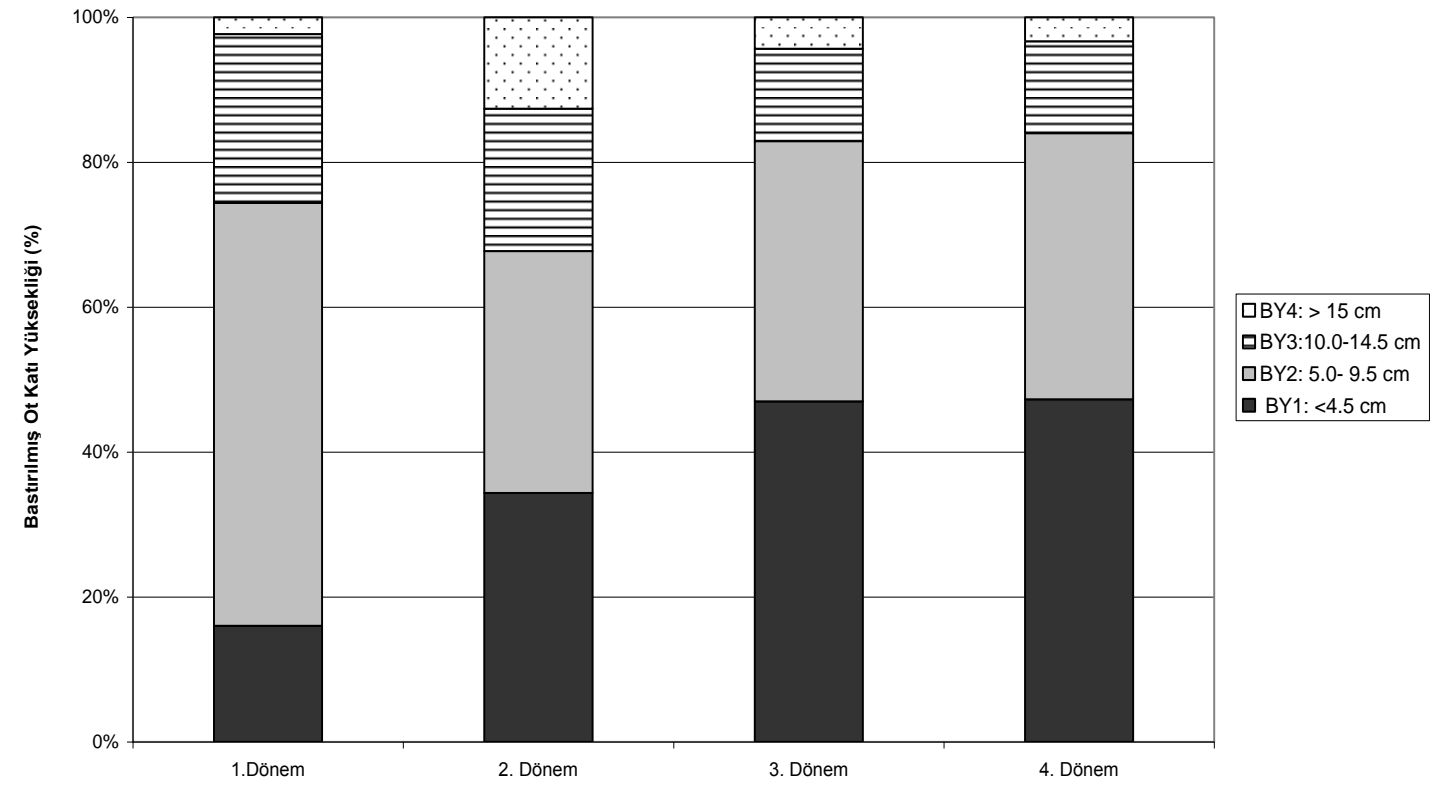

Şekil 2. Orta yoğun otlatma sisteminde= OO; dört farklı mera bastırımış ot katı yükseklik grubunun, dört farklı gözlem tarihinde ortaya çıkma sıklığı 


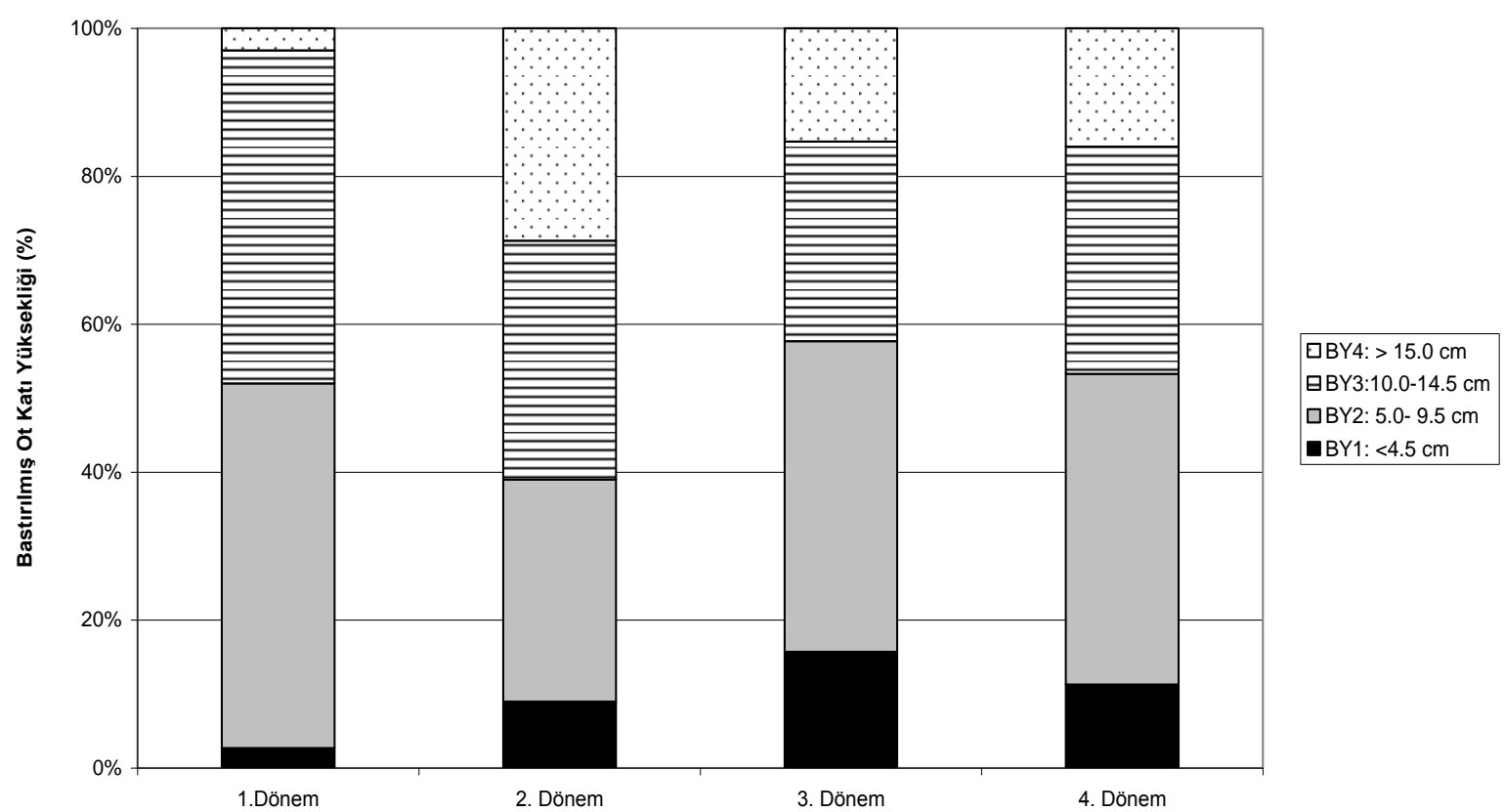

Şekil 3. Hafif otlatma sisteminde=HO; dört farklı bastırılmış o katı yükseklik grubunun dört farklı gözlem tarihinde ortaya çıkma sıklığı

Çizelge 1: Farklı otlatma yoğunluklarında gözlem dönemlerine göre mera bastırılmış ot katı yükseklik grupları dağılımı

\begin{tabular}{|c|c|c|c|c|c|c|}
\hline Otlatma Yoğunlukları & BY Grupları (cm) & 1.Dönem & 2.Dönem & 3.Dönem & 4.Dönem & Ortalama \\
\hline \multirow{4}{*}{$\mathrm{OO}$} & $\leq 4.5$ & 16.0 & 34.3 & 46.7 & 47.3 & $36.1 \mathrm{~A}$ \\
\hline & $5.0-9.5$ & 58.3 & 33.3 & 36.0 & 36.7 & $41.1 \mathrm{~A}$ \\
\hline & $10.0-14.5$ & 23.3 & 19.7 & 12.7 & 12.7 & $17.1 \mathrm{~B}$ \\
\hline & $\geq 15.0$ & 2.3 & 12.6 & 4.7 & 3.3 & $5.7 \mathrm{C}$ \\
\hline \multicolumn{2}{|c|}{ Ortalama } & 24.9 & 24.9 & 25.0 & 25.0 & 24.9 \\
\hline \multirow{4}{*}{$\mathrm{HO}$} & $\leq 4.5$ & 2.7 & 9.0 & 15.7 & 11.3 & $9.7 \mathrm{BC}$ \\
\hline & $5.0-9.5$ & 49.3 & 30.0 & 42.0 & 42.0 & $40.8 \mathrm{~A}$ \\
\hline & $10.0-14.5$ & 45.0 & 32.3 & 27.0 & 30.7 & $33.8 \mathrm{~A}$ \\
\hline & $\geq 15.0$ & 3.0 & 28.7 & 15.3 & 16.0 & $15.8 \mathrm{BC}$ \\
\hline \multicolumn{2}{|c|}{ Ortalama } & 25.0 & 25.0 & 25.0 & 25.0 & 25.0 \\
\hline \multirow[t]{4}{*}{ Tüm Otlatma Grupları } & $\leq 4.5$ & $9.4 \mathrm{FG}$ & $21.7 \mathrm{DE}$ & $31.2 \mathrm{BCDE}$ & $29.3 \mathrm{BCDE}$ & $22.9 B$ \\
\hline & $5.0-9.5$ & $53.8 \mathrm{~A}$ & $31.7 \mathrm{BCD}$ & $39.0 \mathrm{~B}$ & $39.4 \mathrm{~B}$ & $40.9 A$ \\
\hline & $10.0-14.5$ & $34.2 \mathrm{BC}$ & 26.0 CDE & $19.9 \mathrm{E}$ & $21.7 \mathrm{CDE}$ & $25.4 B$ \\
\hline & $\geq 15.0$ & $2.7 \mathrm{G}$ & $20.7 \mathrm{E}$ & $10.0 \mathrm{~F}$ & $9.7 \mathrm{~F}$ & $10.7 C$ \\
\hline \multicolumn{2}{|c|}{ Genel ortalama } & 24.9 & 24.9 & 25.0 & 25.0 & 24.9 \\
\hline
\end{tabular}

Büyük harfler \%1 düzeyinde farklı grupları göstermektedir 


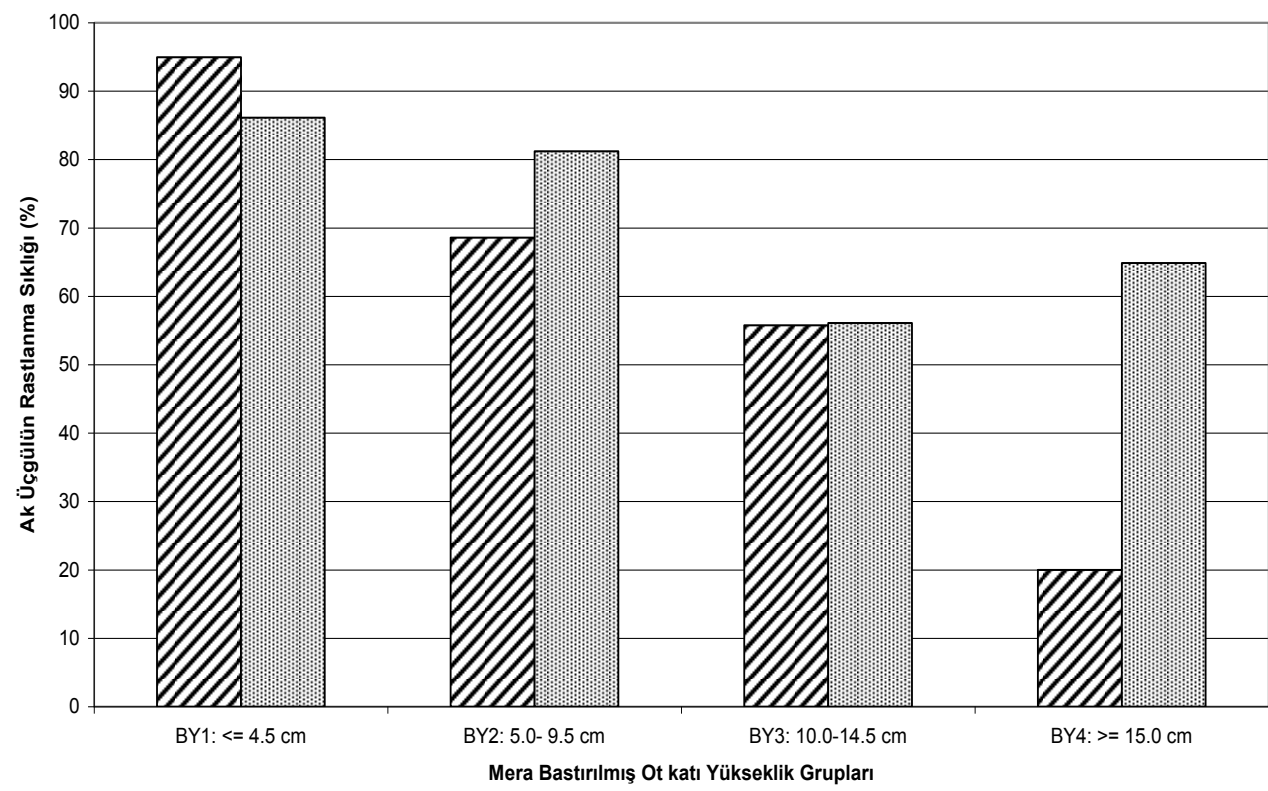

Şekil 4: Üçüncü gözlem döneminde (Yaz dönemi) iki farklı otlatma yoğunluğu (OO ve HO) ve bastırılmış ot katı yüksekliklerinde ak üçgülün rastlanma sıklığı

Çizelge 2: Farklı otlatma sistemlerinde; bastırımış ot katı yükseklik gruplarında ak üçgül rastlanma sıklığı

\begin{tabular}{|c|c|c|c|c|c|c|}
\hline \multirow{2}{*}{$\begin{array}{l}\text { Otlatma } \\
\text { Yoğunlukları }\end{array}$} & \multirow{2}{*}{ BY Grupları (cm) } & \multicolumn{4}{|c|}{ Dönem } & \multirow[b]{2}{*}{ Ortalama } \\
\hline & & 1 & 2 & 3 & 4 & \\
\hline \multirow{5}{*}{ OO } & $\leq 4.5$ & 49.3 & 89.0 & 94.9 & 85.4 & 79.7 \\
\hline & $5.0-9.5$ & 48.2 & 60.1 & 68.6 & 66.4 & 60.8 \\
\hline & $10.0-14.5$ & 29.0 & 59.9 & 55.8 & 38.5 & 45.8 \\
\hline & $\geq 15.0$ & 0.0 & 47.9 & 20.0 & 51.7 & 29.9 \\
\hline & Ortalama & $31.6 \mathrm{~b}$ & $64.2 \mathrm{a}$ & $59.8 \mathrm{a}$ & $60.5 \mathrm{a}$ & 54.0 \\
\hline \multirow{5}{*}{$\mathrm{HO}$} & $\leq 4.5$ & 92.9 & 80.5 & 88.5 & 53.7 & 78.9 \\
\hline & $5.0-9.5$ & 89.8 & 91.8 & 81.2 & 72.7 & 83.9 \\
\hline & $10.0-14.5$ & 58.7 & 52.8 & 56.1 & 52.3 & 54.9 \\
\hline & $\geq 15.0$ & 25.0 & 47.9 & 64.9 & 36.3 & 43.5 \\
\hline & Ortalama & $66.6 \mathrm{a}$ & $68.3 \mathrm{a}$ & $72.7 \mathrm{a}$ & $53.8 \mathrm{a}$ & 65.3 \\
\hline \multirow[t]{5}{*}{$\begin{array}{l}\text { Tüm Otlatma } \\
\text { Grupları }\end{array}$} & $\leq 4.5$ & 71.1 & 84.8 & 91.7 & 69.6 & $79.3 \mathrm{a}$ \\
\hline & $5.0-9.5$ & 69.0 & 75.9 & 74.9 & 69.6 & $72.4 \mathrm{a}$ \\
\hline & $10.0-14.5$ & 43.9 & 56.4 & 55.9 & 45.4 & $50.4 \mathrm{~b}$ \\
\hline & $\geq 15.0$ & 12.5 & 47.9 & 42.5 & 44.0 & $36.7 \mathrm{C}$ \\
\hline & Genel Ortalama & 49.1 & 66.2 & 66.3 & 57.1 & 59.7 \\
\hline
\end{tabular}

Küçük harfler \%5 düzeyinde farklı grupları göstermektedir 
Şekil 4'de ak üçgülün farklı otlatma yoğunluklarına göre, yaz döneminde (3. Dönem) bastırılmış ot katı grupları içinde rastlanma sıklığı görülmektedir.

İki farklı otlatma yoğunluğunda, dört farklı dönemde ve farklı bastırılmış ot katı yüksekliklerinde ak üçgülün rastlanma sıklığına ilişkin değerler ve anlamlılık durumu Çizelge 2' de verilmiştir.

Çizelge 2'ye göre, farklı otlatma yoğunlukları altında, dört farklı dönem ve bastırılmış ot katı yüksekliklerinde ak üçgülün merada rastlanma sıklığ bakımından, "BY grupları" ve "Otlatma yoğunluğuDönem" interaksiyonu açısından gruplar arasındak farklılık \% 5 düzerinde istatistiksel olarak anlamlı bulunmuştur. Diğer faktör ve muhtemel ikili ve üçlü interaksiyonların ortalamaları arasında istatistiksel olarak anlamlı fark bulunmamaktadır.

Ak üçgülün rastlanma sıklığı bakımından BY yükseklik grubu ortalamaları incelendiğinde, BY1 ve BY2 gruplarının her ikisinin aynı anlamlılık grubunda yeraldığı, BY1 in en yüksek (\% 79.3) değere sahip olduğu, bunu \% 72.4 ile BY2'nin izlediği, en düşük BY4'de grubunda belirlendiği (\% 36.7) görülmektedir.

"Otlatma yoğunluğu x Dönem" arasındaki ikili interaksiyonda ise ak üçgülün rastlanma sıklığının istatistiksel olarak farklılığının anlamlı olması sadece OO sisteminin 1. döneminden kaynaklanmaktadır. OO sisteminde en düşük rastlanma sıklığı 1. dönemde (\% 31.6) karşımıza çıkmaktadır. Her ne kadar $\mathrm{HO}$ sisteminde 3 . dönemde ak üçül rastlanma sıklığı en yüksek olsa da, OO sisteminin 1. dönemi dışındaki diğer dönemlerin ortalamaları istatistiksel olarak aynı grupta yer almaktadırlar

\section{Tartışma}

Daha önce yapılan araştırmalarda ağırlıklı olarak biçme işlemi ile otlatma arasındaki problemlerin neler olduğu araştırılmış ve otlatmanın meraya olan etkileri karşılaştırılmıştır.

Bitki topluluğu ve hayvan otlaması bir sistem bütünlüğü oluşturur. Meranın sunduğu ot (yem) miktar hem hayvanların otladığı yemin kalitesi hem verim hem de mera bitki örtüsünün yapısı üzerinde etkilidir (Milne ve Fisher 1993). Mera hayvanlarının farklı otlama alışkanlıkları mera bitki örtüsünde kısa ve uzun bitki toplulukları oluşturmaktadır. Sığırlarla yapılan bu çalışmada, farklı otlatma yoğunlukları altında mera örtüsünün yapısında gözle görülür bir değişim sağlanmıştır ve bu değişim "otlatma yoğunluğu x BY grubu" ve "BY Grubu x dönem" interaksiyonlarının \% 1 düzeyinde (P:0.00) istatistiksel olarak anlamlı olmasıyla açıklanabilir.
Farklı otlatma yoğunluklarında, özellikle hafif otlatma altında, hayvanların seçici otlama alışkanlıkları ile hem bitki örtüsünün gelişim dönemleri hem de bastırılmış ot yüksekliği bakımından heterojen yapılı "farklı bitki adacıkları" (patch) şeklinde yapılar oluşmaktadır. Bu bulgular Bakker (1998) ile uyum göstermektedir. Her ne kadar otlatma yoğunluğunun azaltılması ile flora-fauna bakımından zengin heterojen bir bitki örtüsünün oluşumu sağlanabilse de, gelişen uzun boylu bitkilerin bulunduğu bitki topluluklarındaki yüksek rekabet etkisi bazı bitki türlerinin gelişimi üzerine olumsuz etki edebilmektedir (Lötscher 1994).

$\mathrm{Bu}$ araştırmada, farklı otlatma yoğunlukları sonucu oluşan farklı bastırılmış ot katı yükseklik gruplarının ak üçgülün gelişimi ve bu gruplardaki görülme sıklığı üzerine etkisi de gözlenmiştir. Fakat otlatma yoğunluğu ya da otlatma yoğunluğu ile diğer faktörler arasındaki ikili veya üçlü interaksiyonlarda farkııı̆ın ak üçgülün rastlanma sıklığı üzerine etkisinin istatistiksel olarak anlamlı olmadığı bulunmuştur. Ancak ak üçgülün merada rastlanma sıklığının farklı $B Y$ gruplarında istatistiksel olarak anlamlı derecede $(P$ : 0.013) farklı olduğu belirlenmiştir. OO otlatmada 4,5 cm'den kısa bitki yükseklik grubunda ak üçgülün daha yüksek oranda $(\% 79,3)$ rastlandığı saptanmıştır. Her ne kadar farklı otlatma yoğunluklarının farklı BY gruplarında ak üçgülün rastlanma sıklığı üzerine etkisinin istatistiksel olarak anlamlı etkisi olduğu belirlenmemiş olsa da, orta yoğun otlatmada artan bitki örtüsü yüksekliklerinde ak üçgülün ortaya çıkma sıklığının azalma eğiliminde, BY4'te hafif otlatmada orta otlatmaya göre daha yüksek seviyede olduğu görülmektedir (Çizelge 2).

Üçüncü dönemde $\mathrm{OO}$ sisteminde BY4 yükseklik grubu \% 4.7 oranıyla bitki örtüsü içinde HO'ya göre (\%15.3) oldukça düşük bir oranda kalmaktadır. Bu oran içinde de ak üçgülle karşılaşma sıklığı HO'ya göre daha düşük düzeyde bulunmaktadır (OO için \%20,0; $\mathrm{HO}$ için \%64,9). Cid ve Brizuela 1998'de yaptıkları çalışmada, farklı otlatma sistemlerinde çok derinden otlanan alanlarda birim alanda daha az toplam biyolojik verim oluşturulduğunu tespit etmişlerdir. Çalışmamızda biyolojik verim değerlendirilmemiştir, ancak bu bulgumuz bahsedilen literatür ile paraleldir

Ak üçülün merada ortaya çıkma sıklığına, morfoloji, mera karışımındaki diğer bitkiler, merada otlatma baskısı ve ışık alma durumu gibi birçok faktör etki edebilir. En önemli etki eden faktör, ışık miktarı ve ışığın kalitesidir. Klorofil özellikle mavi ve kırmızı dalga boyları arasındaki ışığı absorbe etmektedir (Sheehy ve ark. 1983). Yüksek boylu bitki gruplarında ışığın yeşil bitki kütlesi tarafından büyük bir kısmı absorbe edildiği ya da yansıtıldığı için, alt tarafta kalan bitkilere daha az ışık enerjisi ulaşmaktadır (Lötscher 1994). 
Ak üçgülün büyümesi, yakınında bulunan komşu bitkiler tarafından gölgelemeyle sınırlandırılabilir (Stoffel 1997). Çok boylanamayan ak üçülün, uzun boylu bitkilerin bulunduğu alanlardaki karışım bitkileri tarafından oluşturulan doğal gölgeleme ile dallanması azalmaktadır (Lötscher 1994). Kısa boylu bitkilerden oluşan bitki gruplarında ışık, sülüklerin bulunduğu yüksekliğe kadar ulaşmakta ve bitki iyi bir şekilde gelişebilmektedir. Ak üçgülün boğumlarından çıkan adventif kökler, sadece toprağın en üst tabakasının içine girdikleri için, orada yeterli su isteği ya da havanın nemini bulabilirler (Nösberger ve Opitz von Boberfeld 1986). Bu da ak üçgülün gelişim ve görülme sıklığını teşvik etmektedir. Yüksek boylu bitki gruplarında ise sülüğe daha az ışı ulaşabilir. Ak üçgül ışık yoğunluğunun azalmasına daha büyük yapraklar oluşturarak tepki gösterse de (Parsons ve ark. 2000) dallanma oranı değişmemektedir (Lötscher 1994).

Çalışmada, ak üçgülün farklı gözlem dönemlerinde (özellikle 1. Dönem yani ilkbaharda) $\mathrm{OO}$ sisteminde yeterince gelişme gösteremediği, en düşük görülme sıklığına sahip olduğu, artan hava sıcaklığı ve otlatma baskısı ile diğer dönemlerde artışa geçtiği görülmektedir. En yüksek ak üçgül görülme sıklığı 3 . dönemde ve $\mathrm{HO}$ sisteminde belirlenmiştir. Bu durum ise, yağışlı geçen 2002 yılı otlatma sezonundan sonra, özellikle yaz döneminde kurak geçen 2003 yılı otlatma mevsimi nedeniyle (Şekil 1), bitkilerdeki büyüme oranın nispeten düşük olması ve özellikle hafif otlatmada bitk örtüsünün hedeflenenden daha fazla otlanması sonucu, kısa boylu bitki yükseklik gruplarının büyük "adacıklar" halinde ortaya çıkmasına bağlanabilir. Bu şekilde oluşan kısa boylu bitki örtüsü ile ak üçgülün ışık gereksinimi yeterince karşılanmış ve oluşan heterojen yapıdaki boşluklar ak üçgülün gelişimini teşvik etmiştir.

"Buğdaygil + ak üçgül" karışım meralarında otlatmadan kaynaklanan yapısal şekil değişikliklerin kısa sürede oluşması beklenemez (Edwards ve ark.1996).

\section{Sonuç}

$\mathrm{Bu}$ çalışma, ak üçgülün daha kısa boylu bitkilerden oluşan mera bitki örtülerinde oluşabilecek boşluklarda daha fazla gelişebileceğini göstermektedir. Oluşabilecek parçalı (mozaik) yapıdaki heterojen mera örtüsü ak üçgülün bu isteğini olumlu bir şekilde etkileyebilir. Mozaik-heterojen bir bitki örtüsü sadece sığır otlatılması ile oluşturulabilir ve devamlılığı sağlanabilir.

Her ne kadar kısa BY gruplarında ve orta yoğun otlatma sisteminde, uzun boylu gruplara ve hafif otlatmaya göre, ak üçgülün görülme sıklığının eğilim olarak daha fazla olduğu belirlenmiş olsa da, farklı otlatma baskılarının bitki örtüsünün gelişimi ve ak üçgülün bundan nasıl etkilendiği üzerine yapılacak daha uzun yılları içeren bilimsel çalışmalara intiyaç vardır.

\section{Kaynaklar}

Bakker J. P. 1998. The impact of grazing on plant communities. P: 137-184 Ed:M. F. Wallis de Vries, J. P. Bakker and Van Wieren. Grazing as a tool in conservation management. Chapman and Hall, London.

Castle M. E. 1976. A simple disc instrument for estimating herbage yield. Journal of the British Grassland Society 31: $37-40$.

Cid M. S. and M. A. Brizuela 1998. Heterogeneity in tall fescue pastures created and sustained by cattle grazing. Journal of Range Management 51: 644-649.

Edwards G. R., A. J. Parsons, J. A. Newman and I. A. Wright 1996. The spatial pattern of vegetation in cut and grazed grass/ white clover pastures. Grass and Forage Science 51: 219-231.

Geisler, G. 1980. Pflanzenbau, Ein Lehrbuch- Biologische Grundlagen und Technik der Pflanzenproduktion. Verlag Paul Parey Berlin und Hamburg.

Keller E. R., H. Hanus and K-U. Heyland. 1999. Knollen- und Wurzelfrüchte, Körner- und Futterleguminosen. Band 3, Verlag Eugen Ulmer GmbH and Co Stuttgart.

Lötscher M. 1994. Austrieb und Entwicklung der Seitentriebe von Weissklee (Trifolium repens L.) - Einfluss der Bewurzelung sowie der Lichtintensität und-qualität. Diss. ETH Zürich.

Milne J. A. and G. E. J. Fisher. 1993. Sward structure with regard to production. In: Haggard RJ \& Peel S (eds.), Grassland Management and Nature Conservation. British Grassland Society Occasional Symposium 28:33-42.

Nösberger J. and W. Optz von Boberfeld. 1986. Grundfutterproduktion. Verlag Paul Parey Berlin und Hamburg.

Opitz von Boberfeld W. 1994. Grünlandlehre. Eugen Ulmer Verlag, Stuttgart.

Parsons A. J., P. Carrere and S. Schwinning. 2000. Dynamics of heterogeneity in a grazed sward. In: Lemaire G, Hodgson J, de Morales A, de F Carvalho PC \& Nabinger C (eds.), Grassland ecophysiology and grazing ecology. CAB International, Oxon, 289-315.

Sheehy J. E., C. Vazzana and F. R. Minchin. 1983. Light Quality, symbiotic nitrogen fixation and growth in white clover plants. Plant and Soil 73,117-128.

Stoffel S. 1997. Überwinterungsfaehigkeit und Frühjahrswachtum von Weissklee (Trifolium repens L.) im Gemenge mit Deutschem Weidelgras (Lolium perenne L.). Diss. Technische Universitaet München.

\section{İletişim adresi:}

Nurdan ŞAHIN DEMIRBAĞ

Ankara Üniv. Ziraat Fak.Tarla Bitkileri Bölümü - Ankara

Tel: 03125961639

E-posta:nsahin@agri.ankara.edu.tr 
